
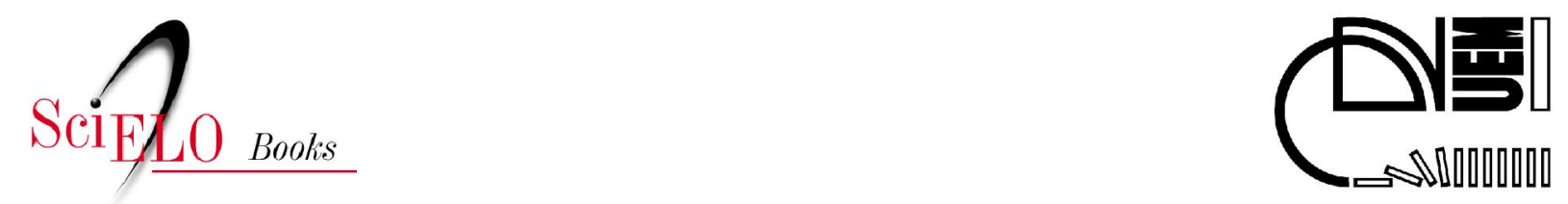

\title{
I. Introdução ao fenômeno da colonização agrária
}

\author{
Paulo Astor Soethe (org.) \\ Daniel Martineschen (coord.) \\ Caio Heleno da Costa Pereira \\ Dionei Mathias \\ Elisete Antoniuk \\ Fernanda Boarin Boechat \\ Frederico Füllgraf \\ Natasha Pereira da Silva \\ Sibele Paulino \\ Sirlene Nair Neubauer \\ (transl.)
}

\section{SciELO Books / SciELO Livros / SciELO Libros}

SOETHE, PA., org. MARTINESCHEN, D., et al., transl. KOHLHEPP, G. Introdução ao fenômeno da colonização agrária. In: Colonização agrária no Norte do Paraná: processos geoeconômicos e sociogeográficos de desenvolvimento de uma zona subtropical do Brasil sob a influência da plantação de café [online]. Maringá: Eduem, 2014, pp. 29-32. ISBN 978-85-7628-655-4. Available from SciELO Books $<\underline{\text { http://books.scielo.org }>\text {. }}$

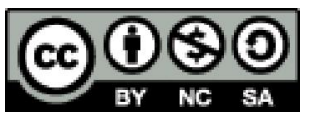

All the contents of this chapter, except where otherwise noted, is licensed under a Creative Commons Attribution-Non Commercial-ShareAlike 3.0 Unported.

Todo o conteúdo deste capítulo, exceto quando houver ressalva, é publicado sob a licença Creative Commons Atribuição Uso Não Comercial - Partilha nos Mesmos Termos 3.0 Não adaptada.

Todo el contenido de este capítulo, excepto donde se indique lo contrario, está bajo licencia de la licencia Creative Commons Reconocimento-NoComercial-CompartirIgual 3.0 Unported. 


\section{INTRODUÇÃO AO FENÔMENO DA COLONIZAÇÃO AGRÁRIA ${ }^{4}$}

Entre o início e meados do séc. XX, a colonização agrária em territórios tropicais, subtropicais e extratropicais da América Latina suscitou efeitos de desenvolvimento com intensidades regionais diversas.

Enquanto que, até o início do séc. XIX, os assentamentos coloniais restringiam-se apenas às bordas continentais e aos territórios da Alta Cultura indígena no Planalto Andino, após a independência de países como a Argentina e o Brasil, principalmente a partir de meados do séc. XIX, com a chegada das primeiras levas de imigrantes europeus, observamos uma expansão da ocupação territorial de direcionamento limitado. As incursões isoladas, em sentido centro-periferia, alcançaram êxito apenas parcial.

Até meados da década de 1950, predominaram em territórios florestais da América Latina, a ocupação e colonização espontânea, isto é, não dirigida. Apesar do efeito psicológico do ato da posse da terra, para a maioria dos colonos no papel de posseiros, seu peso econômico frequentemente limitou-se às culturas de subsistência, sob condições assaz primitivas, além de isoladas, sem quaisquer vínculos com mercados.

Somente em épocas mais recentes e devido ao aumento da pressão demográfica e das tensões sociais, começa a surtir efeito o planejamento regional de corte estatal, que no contexto da Reforma Agrária alavanca projetos de colonização de variada extensão.

A pesquisa geográfica da colonização agrária e de suas especificidades regionais, seja de caráter espontâneo, seja dirigida por agentes privados ou da esfera pública, desde a publicação dos trabalhos de Bowman, na década de 1930 (BOWMAN, 1931, 1932 e 1937) $)^{5}$, que ilustravam comparativamente o patamar de desenvolvimento no continente latino-americano em escala global, adquiriu notável importância.

Desde então, foi investigada a colonização pioneira em territórios de floresta pluvial do istmo centroamericano, do noroeste colombiano, das florestas do Planalto Andino, entre a Colômbia e a Bolívia, do leste paraguaio, da Patagônia oriental ${ }^{6}$, do extremo nordeste argentino, assim como do Sudeste e Sul brasileiros $^{7}$

No início da década de 1960, encerravam-se no Brasil tanto o ciclo da ocupação e colonização dos últimos espaços extra-amazônicos de floresta tropical pluvial, como também o assentamento expansivo em territórios de floresta subtropical da região Sul do país. No decurso espontâneo desses processos de desenvolvimento de grandes extensões territoriais, marcados por motivações econômicas diferenciadas e protagonizados pelos mais diferentes agentes de colonização, foram finalmente ocupados e colonizados o oeste do estado de São Paulo, a foz do Rio Doce e o sul da Bahia, o 'Mato Grosso' de Goiás, o território do Alto Uruguai, no norte do Rio Grande do Sul, o oeste de Santa Catarina, além do norte e do oeste do Paraná.

As pré-condições naturais destes processos, nas zonas climáticas sempre-úmidas e tropicais de umidade alternada, muito diferentes umas das outras, ocorreram sobre solos com graus de fertilidade muito diferenciados. Também a velocidade e intensidade das ocupações decorreram da pressão demográfica nas regiões de origem e segundo diferentes objetivos da colonização, dos quais eram portadoras camadas sociais com interesses diferenciados, sem falar de sua inserção em ciclos

4 Tradução de Frederico Füllgraf.

5 A título de comparação, veja-se também os estudos regionais detalhados de numerosos especialistas internacionais, em Joerg (1932).

6 Argentina [N.T.]

7 Entre outros, Sandner (1961, 1964) e Sandner/Nuhn (1971); Parsons (1968); Brücher (1968); Sick (1963); Maas (1969); Monheim (1965 e 1968); Schoop (1970); Dozier (1969); Wilhelmy (1940, 1941, 1949a); Lauer (1961), Golte (1973); Eriksen (1970); Eidt (1971); Waibel (1949, 1955a e 1955b), Monßeig (1952), Pfeifer (1966a e 1966c, 1967), Kohlhepp (1966a e 1966b). - Sobre o tema, de modo geral, ver Schauff (1959) e Caviedes (1971). Pesquisas sobre a recente ocupação da região amazônica brasileira entre outras, as do próprio Autor - não foram levadas em consideração. 
econômicos marcados por fortes oscilações dos mercados agroexportadores. Dentro das limitações apontadas, brotam zonas de colonização pioneira, cuja dinâmica, marcada pela especulação imobiliária e disputas pela posse da terra, e como consequência do modo de produção extrativo, em pouco tempo foi suplantada pelas manifestações da hollow frontier ${ }^{8}$, isto é: exaustão dos solos, quebra das colheitas e, com isso, deslocamento das prioridades produtivas, transformação das áreas de cultivo em pastos para a criação extensiva de gado e, finalmente, o abandono da região pelos próprios assentados.

Em oposição à dinâmica conhecida de processos geoculturais de ocupação uniforme de grandes extensões, está o desenvolvimento muito mais diferenciado do Norte do Paraná, objeto da presente pesquisa, que se expande sobre uma área de $57.000 \mathrm{~km}^{2}$ ao sul do Rio Paranapanema - divisa natural dos Estados do Paraná e de São Paulo - , delimitado a oeste pelo Rio Paraná, que a partir de Guaíra estabelece a fronteira natural com o Paraguai.

Aqui, a fronteira climática da cafeicultura estabelece certo critério de delimitação em direção ao sul, que se confunde com a ocorrência anual de geadas. Em bases naturais de clima e vegetação, esta delimitação será acentuada pela convergência de duas formas de organização agrícola, marcadas por elementos populacionais, formas econômicas e metas de produção distintas:

1. A 'Cafeicultura', com sua estrutura social particular no Norte do Paraná, constituída por contingentes populacionais luso-brasileiros, originários de São Paulo, Minas Gerais e do Nordeste, bem como pelos descendentes de trabalhadores italianos nos cafezais paulistas. Tratase de uma formação econômica de corte tropical, voltada para o mercado mundial, e que a partir do Norte do Paraná se expande em sentido sudoeste;

2. 'Forma de produção agrícola subtropical' estabelecida nos territórios ao sul da região cafeeira e protagonizada pelos descendentes de imigrantes alemães e italianos, originários do Rio Grande do Sul e Santa Catarina, que se afirmou como organização autônoma de melhoramento do sistema de cultivos alternados e da produção de alimentos.

De acordo com o fluxo migratório dos colonos originários no estado de São Paulo, com sucessivas levas que se deslocaram no tempo e no espaço em sentido leste-oeste, é possível interpretar a geografia do Norte do Paraná da seguinte forma (Mapa 1):

a) O Norte Velho, cuja ocupação se iniciou de forma aleatória desde a segunda metade do séc. XIX, e que se estende da divisa com São Paulo, a leste, até o Rio Tibagi, a oeste;

b) O Norte Novo, colonizado sistematicamente apenas desde 1930 com poucas exceções, e que em sentido oeste toca uma linha geográfica que vai do Rio Pirapó até o joelho do Ivaí;

c) O Norte Novíssimo, ocupado a partir da década de 1940, embora efetivamente colonizado apenas a partir da década de 1950, consta como o território de colonização mais jovem do estado. Essa região situa-se a oeste do Norte Novo e ao norte do rio Ivaí, assim como ao sul do rio Paranapanema, bordejando o rio Piquiri. Devido ao seu desenvolvimento no setor norte, a microrregião de Campo Mourão costuma ser agregada ao Norte Novíssimo.

A presente pesquisa, contudo, centra seu foco sobre o território situado a oeste do rio Tibagi. Em oposição ao Norte Velho, que fora ocupado espontaneamente segundo o tradicional sistema da cafeicultura paulistana, o desenvolvimento do Norte Novo funda-se sobre a colonização privada, organizada em torno da pequena e média propriedades. Ocorre que a crise da economia mundial e a crise do setor cafeeiro haviam forçado uma reestruturação da estrutura de propriedade rural no frontier brasileiro", pois no Norte Novíssimo, além das atividades de algumas empresas privadas e da posse espontânea da terra, prevaleceu sobretudo a colonização dirigida pelo Estado.

Durante a crise do café - momento que coincidiu com o início do processo de colonização não especulativo, marcado por excelente planejamento regional - o território situado nos limites da zona climática tropical, ao sul da zona hegemônica de economia de plantações apontada por Pfeifer (1966a), devido à sua importância para a conformação de territórios de cultivo no Novo Mundo, ofereceu uma excelente oportunidade no Norte Novo para uma empresa britânica de colonização.

8 Fronteira oca ou última fronteira, como, p. ex. A ocupação de Rondônia, segundo James (1938, [N.T.]).

9 Aqui subentendido como fronteira agrícola [N.T.] 
Hoje $^{10}$, quando todos os esforços de ocupação territorial no Brasil estão concentrados na Amazônia inexplorada e são instaladas pequenas e médias empresas ao longo de estradas interestaduais e eixos de inclusão territorial, as diretrizes para a colonização, os processos de desenvolvimento e as experiências colhidas no Norte do Paraná voltam a ganhar importância.

Exceção feita a alguns projetos isolados do governo revolucionário do México, a colonização agrária dirigida, em uma área com mais de $12.500 \mathrm{~km}^{2}$, a oeste do rio Tibagi, foi um dos primeiros e raros grandes projetos de desenvolvimento regional na América Latina até a década de 1950, e constituiu-se em coluna vertebral do desenvolvimento no Norte Novo e Novíssimo do Paraná, capaz de transformá-lo, com o boom cafeeiro do pós-guerra que se iniciara 25 anos antes, numa das zonas de colonização pioneira mais dinâmicas e brilhantes da América Latina (DOZIER, 1969, p. 9; JAMES, 1969, p. 494). No curso de apenas 20 anos, mais de 2 milhões de pessoas emigraram para essa região onde, apesar das quebras de suas colheitas devido às geadas, desenvolveu-se não apenas o mais importante polo cafeeiro do Brasil, mas de todo o mundo ${ }^{11}$, pois suas safras recordes chegaram a colher até 25 por cento de toda a safra mundial de café.

O cerne da presente pesquisa é, portanto, a análise do fluxo temporal e espacial de processos em suas variadas estratificações da colonização agrária, e dos fatores econômicos, políticos e socioeconômicos e ambientais que influíram em seus efeitos regionais. A ênfase está nos processos de desenvolvimento econômicos e sociogeográficos ocorridos no contexto da expansão da cafeicultura e dos problemas a ela relacionados. A dependência do café do mercado mundial, como também a tentativa de dirigir a produção em escala nacional e internacional acabaram por influenciar as fases desse desenvolvimento e a intensidade das respectivas reações à configuração das áreas de cultivo.

Mobilidade espacial e social de distintas camadas sociais e grupos etno-sociais deverão ser analisados de acordo com seus impactos sobre a engrenagem social das zonas pioneiras e suas transformações até os dias atuais. Devido a que essas zonas se caracterizam por poucos centros comerciais que se encontram ainda no início do processo de industrialização, a questão do desenvolvimento urbano no Norte do Paraná será abordada apenas tangencialmente nos quesitos que têm relevância para os processos de desenvolvimento rural.

A integração tardia dos territórios da fronteira histórica entre os domínios espanhol e português ao espaço geoeconômico do Brasil durante a crise do café, o predomínio monocultural da cafeicultura na fase seguinte, como também a geração dos atuais problemas estruturais de caráter socioeconômico - cuja causa é uma agricultura marcada por fatores econômicos e tendências de diversificação, e também pela busca por novos territórios apropriados - são elementos que ordenam o encadeamento da pesquisa.

Devido ao estágio de desenvolvimento muito recente da região, a pesquisa científica sobre o Norte do Paraná, nestes meados dos anos 1970, dá apenas seus primeiros passos. Para situá-la, são de suma importância as pesquisas fundacionais, com estudos da geografia física e da geologia da região, escritos por Maack. Devido à estrutura econômica e social diversa, Waibel (1949) não incluiu o Norte do Paraná em sua investigação da colonização europeia na Região Sul do Brasil. Já Monbeig (1952), nos seus trabalhos, concentrou-se em São Paulo, tecendo algumas referências (1935) ao estágio de desenvolvimento do norte paranaense de então, mas apenas de passagem e para efeito comparativo. Exceção feita a alguns ensaios valorosos do início da década de 1950, de estudantes de Waibel, e de algumas abordagens gerais ${ }^{12}$, os estudos geográficos brasileiros tampouco deram muita importância a essa região negligenciada pelas pesquisas, que à época tinham outras prioridades.

Neste sentido, o presente trabalho também é o resultado de extensos deslocamentos pelo território, grande número de entrevistas pessoais e levantamento estatístico em alguns municípios, como também de observações e mapeamentos, triagem de imagens aéreas e emprego de material de arquivos e fontes diversas.

Seu objetivo não é apenas analisar a sucessão de processos de desenvolvimento de geografia agrária, além de suas causas e efeitos na zona de influência da cafeicultura. Mais do que isso, ela também pretende

10 O autor escreve durante a década de 1970. O leitor deve considerar que os prognóstocos e afirmações do autor foram feitos nessa época, e devem ser comparados com o que realmente aconteceu desde então. [N.T.]

11 Na média anual dos doze anos entre 1961 e 1972: 50\% da produção brasileira de café.

12 Bernardes (1952); C. Bernardes (1950, 1953); Valverde (1956); Müller (1956); França (1956). Do lado americano: Dozier (1956), Dambaugh (1959); a partir de um ponto de vista sociológico e econômico: Margolis (1970, 1972), bem como Nicholls e Paiva (1969) e Nicholls (1970). 
contribuir ao debate sobre a problemática do planejamento regional em novas áreas de assentamento voltadas para o mercado mundial, e à questão das zonas pioneiras de colonização, cujo estágio de desenvolvimento, de um lado, é marcado por dinâmica e mobilidade social e, de outro, por fatores de instabilidade exógenos e endógenos, conflitos de interesse e estruturas de dependência. Além disso, seu objetivo é contribuir ao estudo das mudanças estruturais e tendências de diversificação geoagrárias, tanto espontâneas como dirigidas, no campo das monoculturas tropicais, que são de fundamental importância para a minimização de riscos de ordem natural e econômica, e a melhoria das condições socioeconômicas nos países em desenvolvimento. 